and from that time on had no recurrence of epigastric hyperalgesia. The pain following hysterectomies, oophorectomies, and other uncomfortable operations on the uterus and adnexa have been similarly relieved by deep muscular injections into the hyperalgetic areas. In a number of cases I have had entirely satisfactory results from the use of the cocain alone, and latterly with norocain, thus showing that it is sufficient to overcome what I look on as entirely normal but none the less painful muscular irritability, and to do so without hypnotics addressed to the general consciousness. Even in some instances, as in a case of a firm intra-uterine pack following a curettage, in which the superficial hyperalgesias were also present, the inhibition of the muscular irritability within the involved superficial areas was followed also by cessation of the pain referred by the patient to the uterus. From this experience, interpreted in the light of the facts which I have presented, I arrive at the object that $\mathbf{I}$ had in preparing this paper, and that was to emphasize, by brief summary, the treatment of various pains of visceral origin.

TREATMENT OF POST-OPERATIVE, PARTURIENT AND OTHER PAIN OF VISCERAL ORIGIN

1. Visceral pain, so far as the abdomen, pelvis and thorax are concerned, is expressed chiefly but not exclusively in the autonomic algetic areas of the protective walls covering the respective viscera, such algetic areas corresponding in extent with the peripheral distribution of the autonomic nerves coincidently with the peripheral distribution of the respective spinal nerves in the muscles and subserous connective tissue.

2. These distributions can generally be determined clinically by determining the area of partial hyperalgesia.

3 . The pain itself, consisting chiefly of hyperexcitation of muscle irritability, can be partially and, as a rule, entirely, inhibited by inhibiting the muscle sensibility in the hyperalgetic areas.

4. The same principle applies to the peripheral control of pain originating in the parturient uterus, with the difference that the infiltration of succeeding mussle zones must be practiced with the corresponding advance of the delivery.

\section{METHOD OF TREATMENT}

My method of treatment, briefiy stated, is as follows: 1. Have prepared a standard analgetic and local anesthetic mixture as follows:

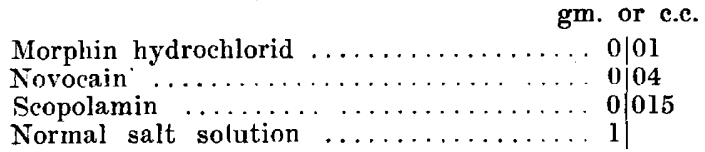

This represents a single dose which, before administration, is further diluted with physiologic salt solution to permit of its distribution by numerous deep punctures with an ordinary hypodermatic needle into the hyperalgetic areas.

2. For analgesia, after thoroughly cleansing the integument, all of the mixture is injected into the muscular layer, several punctures being employed and care being taken to make them at points that approximately define the circumference of the hyperalgetic area. The analgetic effects will be realized within from five to ten minutes, and in consequence of the presence of the scopolamin, will be continued often from six to eight hours, while in some instances they will be permanent.

3. For local anesthesia, the same solution is used in the same way, with the exception that it is discharged into the subcutaneous connective tissue at points that approximately define the circumference of the area that it is desired to anesthetize, The sensibility will disappear in from five to eight minutes and will remain absent for a period varying from an hour to three hours.

4. The infiltration treatment practiced by Schleisinger, Hecht and others in sciatica involves the injection of large volumes of the solution, thus, (a) 10 to 20 c.c. of the normal salt solution reduced to zero (Centigrade); (b) 80 to 100 c.e. of normal salt solution at the temperature of the body; (c) 60 to 120 c.c. of beta-eucain solution at the temperature of the body. Langdon's method of treatment by pure aqueous infiltration involves the use of smaller volumes of fluid.

\section{DISCLAIMER}

Now that I have presented briefly this phase of the manifestation and control of visceral pain, and in view of the tendency to give a wider scope than is intended to a single idea, $\ddot{I}$ wish, in conclusion, to make a few points clear. In the first place (1) the details of the autonomis phenomena are only beginning to be understood; (2) while I believe that these phenomena when once understood may be classed among the clinical constants, I do not believe that they can have a significance that will justify failure to consider all other diagnostic factors; (3) and I recognize the possibility and, under certain obvious circumstances, the desirability of temporary control of pain by the method I have indicated, I do not recognize the possibility that it can ever supplant the rational curative method which always implies the removal of the cause for the cure of the effect.

\section{THE OPEN TREATMENT OF FRACTURES}

S. D. VAN METER, M.D.

Visiting Surgeon to City and County Hospital DENVER

It is admitted that a large proportion of fractures can be successfully treated by manual reduction and by the ordinary external appliances, designed to retain the fragments in place; but we are all familiar with the difficulty of securing and maintaining perfect reduction by these methods. Further, we know now that in many cases in which we have felt sure of having secured a satisfactory reduction, a subsequent radiograph has too frequently proved the error of our conclusions, and shaken our confidence in the time-honored tests of mensuration and palpation. Particularly is this true in fractures of the femur and humerus, in which we have to contend with a large amount of surrounding soft tissues, and especially when the fracture is oblique or comminuted. It is safe to venture the statement that in such cases an anatomic reduction is seldom, if ever, accomplished by the closed method; and if accomplished, it is next to the impossible to retain the fragments in position.

The recognition of these facts has led surgeons to resort to the apparently more radical procedure of the open treatment, which renders reduction comparatively simple and makes it nossible to apply one of the many mechanical devices intended to retain the fragments in position. These devices are numerous, as the archives of surgery give evidence; but they may for practical consideration be divided into two classes, viz., those to be removed after repair of the fracture, and those to be left in situ.

The former have the apparent advantage of leaving no foreign body permanently imbedded in the tissues. The danger of trouble from leaving an aseptic metallic substance at the seat of the fracture has been greatly overestimated, however, and is not to be compared with 
the increased danger of infection common to all devices designed for removal after union has been established. Furtier, it is a physical impossibility to secure perfect immobility with any of this class of appliances, on account of the necesary distance of the fixation bar from points of application to the tragments. Their. external portion makes dressings more difficult, and, if the limb is accidentally harshly touchod, causes the patient pain with more or less distribance of the frasnents.

of the lattar alass. devices designed to be left in situ, none is to be commaled with the steel plate devised by Mr. Arbuthnot Lane in ease of application, the imme-
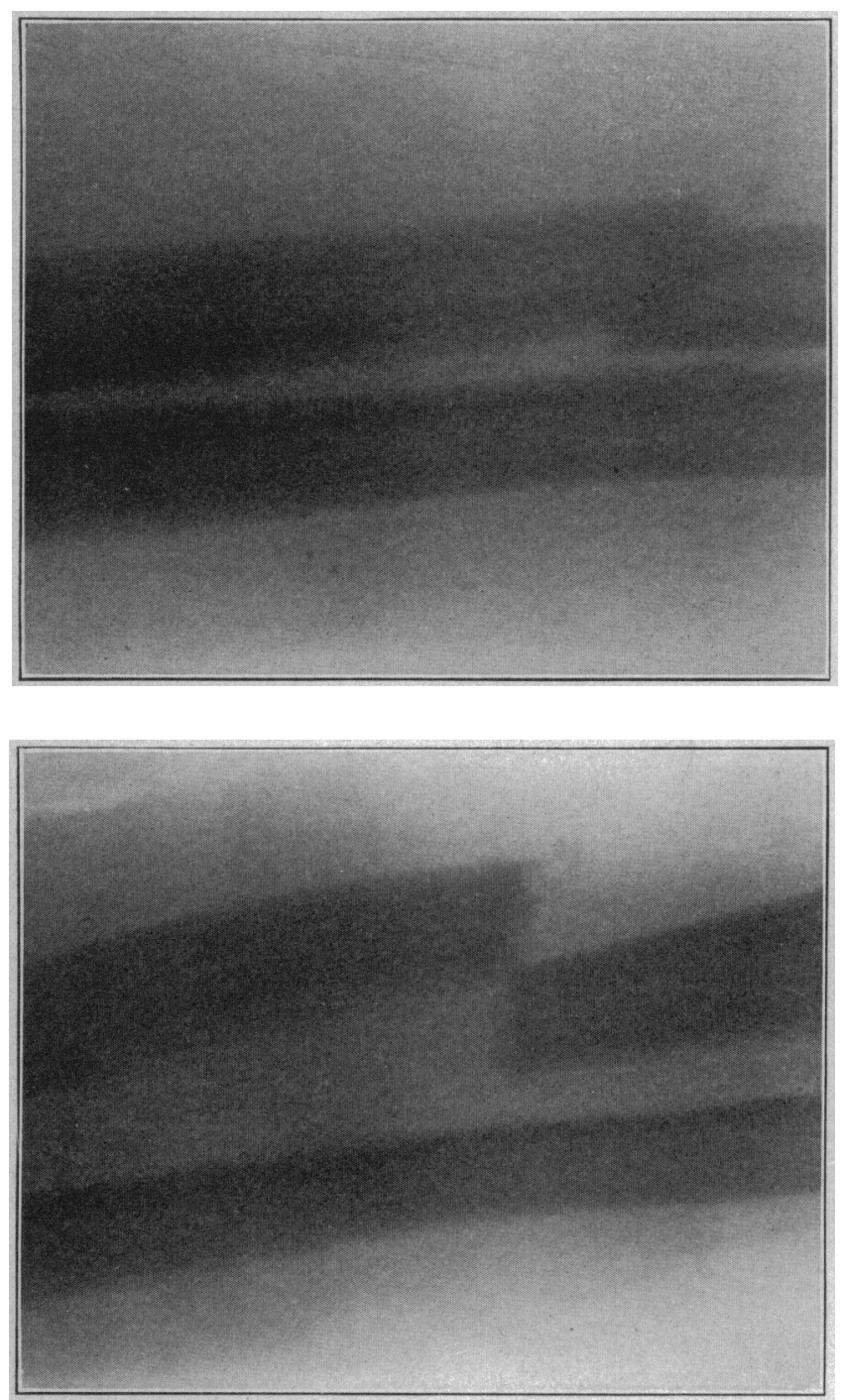

Figs. 1 and 2.-Comnound infected fracture of ladius and ulna

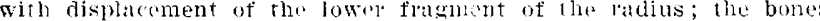
aje slown from two different positions (Case il.

diate perfect immobilization of the fragments and theip satisfactory retention in position. Ther seldom cause any irritation, and, if it hecomes necessary to remove them, this is not difficult.

In using these plates there are sereral points which are wortly of consicleration. Tl:ose of scrupulous asepsis and cireful handling of the soft tissues are so well recognized as hardly necessary to be mentioned. Nothing but the judgment of the operator and the special features of the individual case can determine the best time to operate. It is generally bettur to wait, however, until the tissues have recovered somewhat from the devitalizing effect of the traumatism and attained a certain degree of resictance to infection. 'The solection of the proper drill for the size of the serew is important. A drill which will make a hole just large mough to allow the serew to be driven without splitting the bone. gives the best result. It is not mocesary, howerer, to have the loole so small as to make it difficult to drive the screw "home" with the ondinary screw-driver. $B$ experimenting on a fresh bed-bone one can eacily select
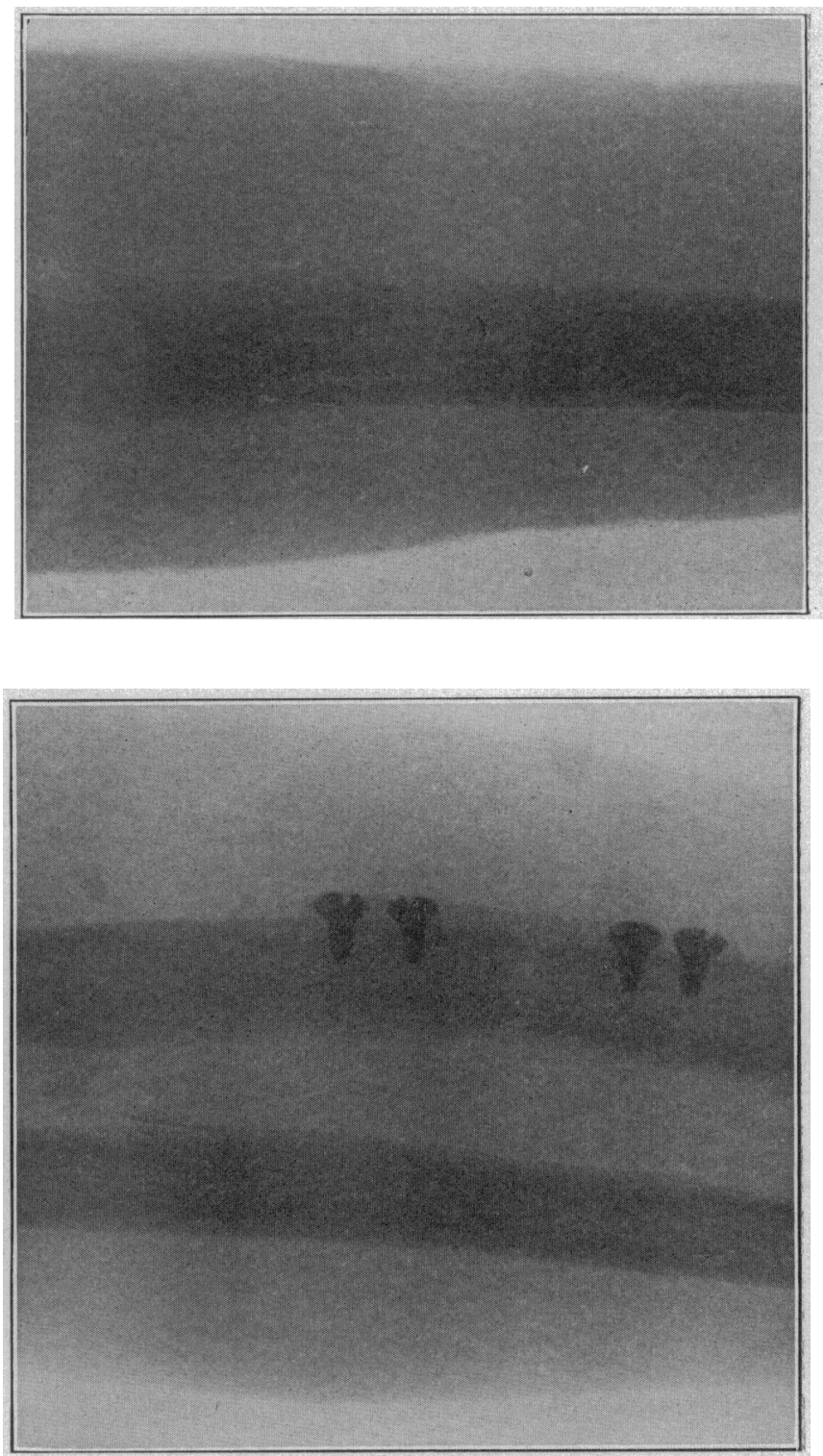

Figs 3 and 4-Tro views of fractures shown in Fimule 1 after

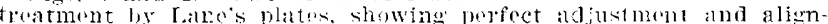
ment of the fractures. 'The climiess of the plates is due to their having been made of aluminum.

the drill arlapted to the screws to be meet. which slould have a "wood" thread with melium clumfer. The retention of the fragments in position while the operator is drilling the first two holes is not alwars an easy task for the assistant. and the specin? forens rlesioner by Mr. Tane for holiling the fragments is undoubtedly superior to the ordinary forceps, althougl one ran cret along very well with the latter. Tn my judgment. a fair trial of the open treatment of properly selected cases of fracture will verify the following conclusions: 

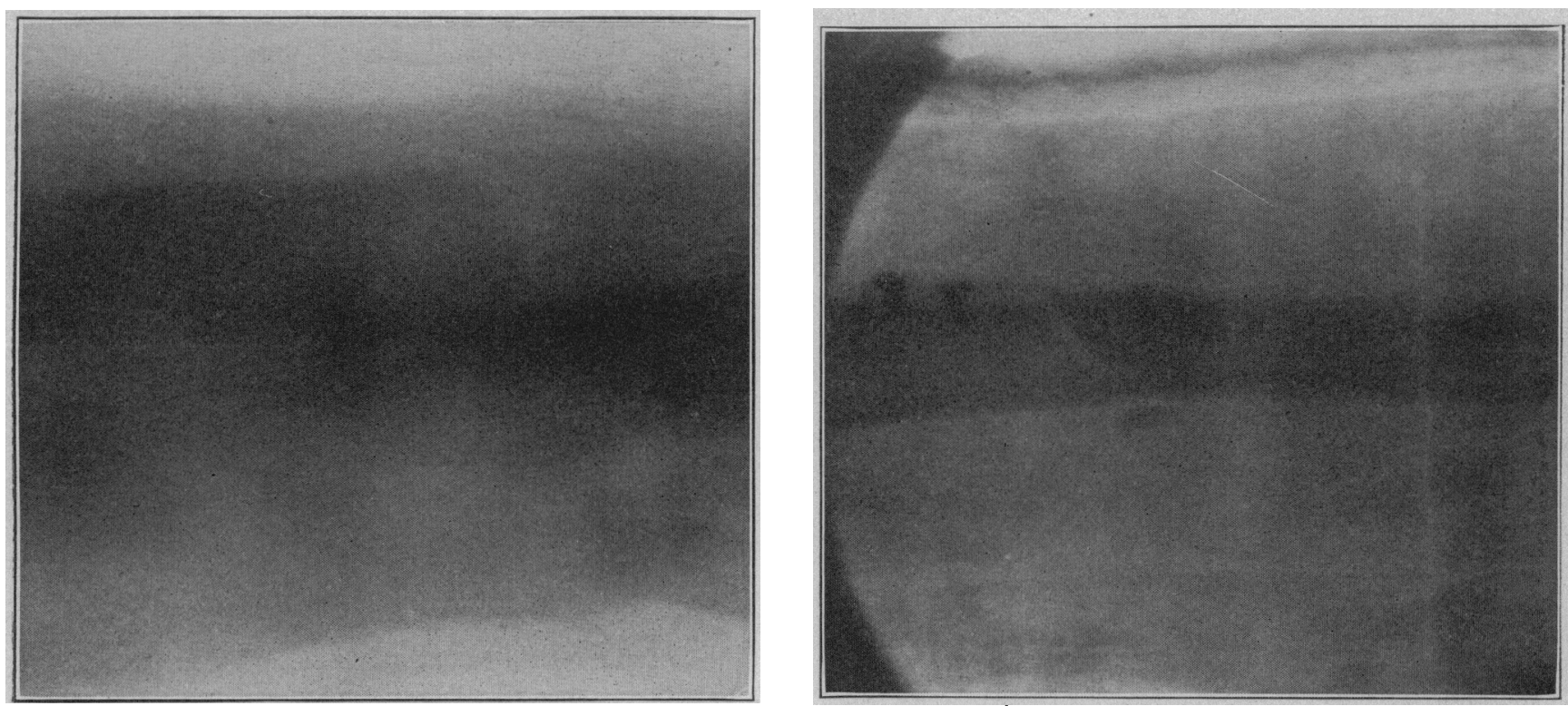

Fig. -.- Fracture of left femur at midde of lower third with the usual hakward displacement of the mpler ond of the lower firament (case 21 . Reduction was thought to has heren aceomplished

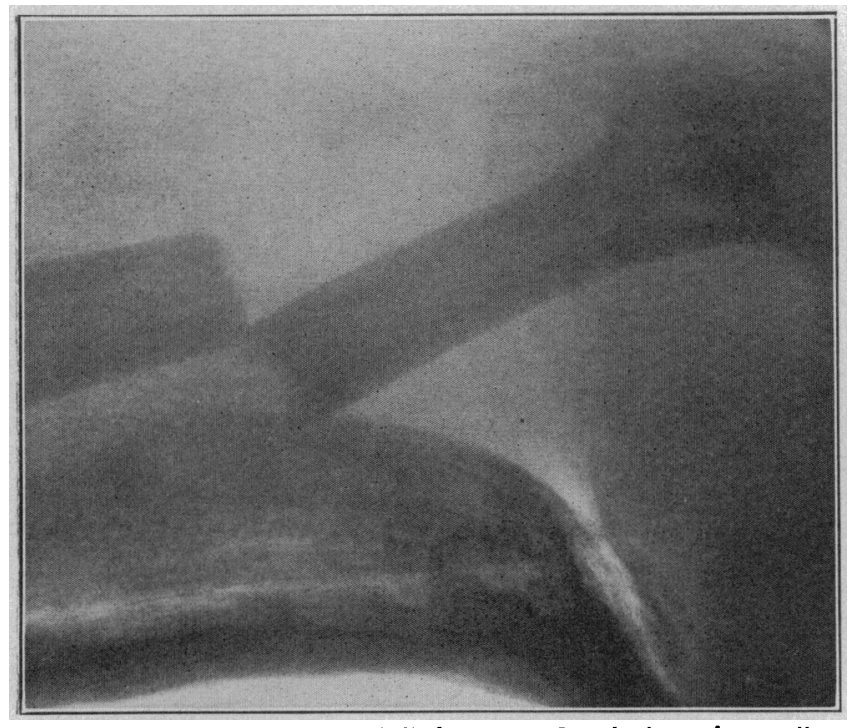

Fig. 6.-Reduction by open operation and the use of the plate of fracture showil in rigure $\tilde{5}$.

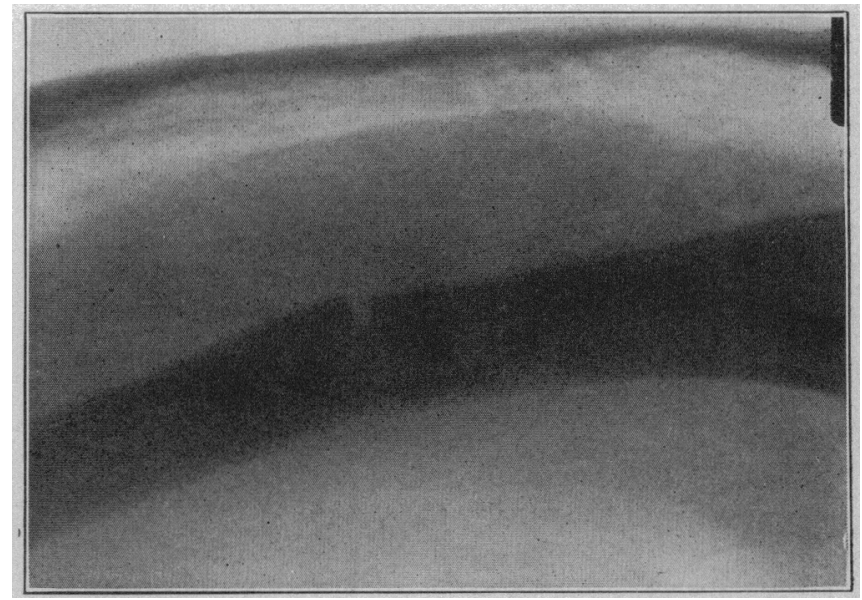

Fig. S.-Reduction of the fracture shown in Figure 7 , by the open mothod; alignment not perfect, but imploved by splints and compresses.

Fip 7 -Fracture of the inft humerus five inches above clbow involving the muscilosilal groove, with warked forward displacement of the lower frimunt (Case 3 ).

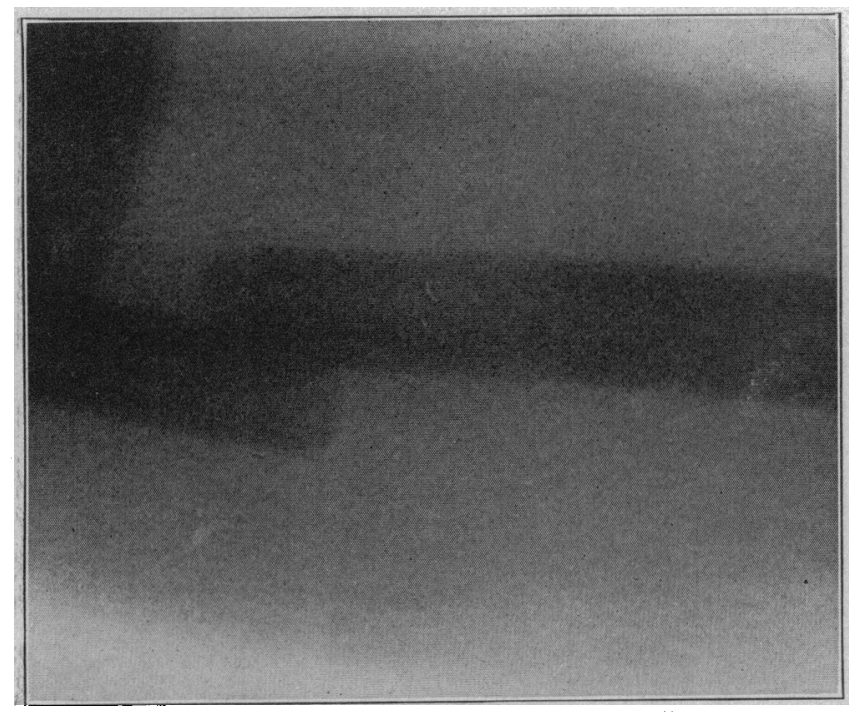

Fin. 9.-Frasture of upper third of left femur. Three unsucess

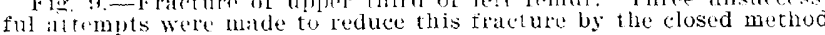
(ciase t)

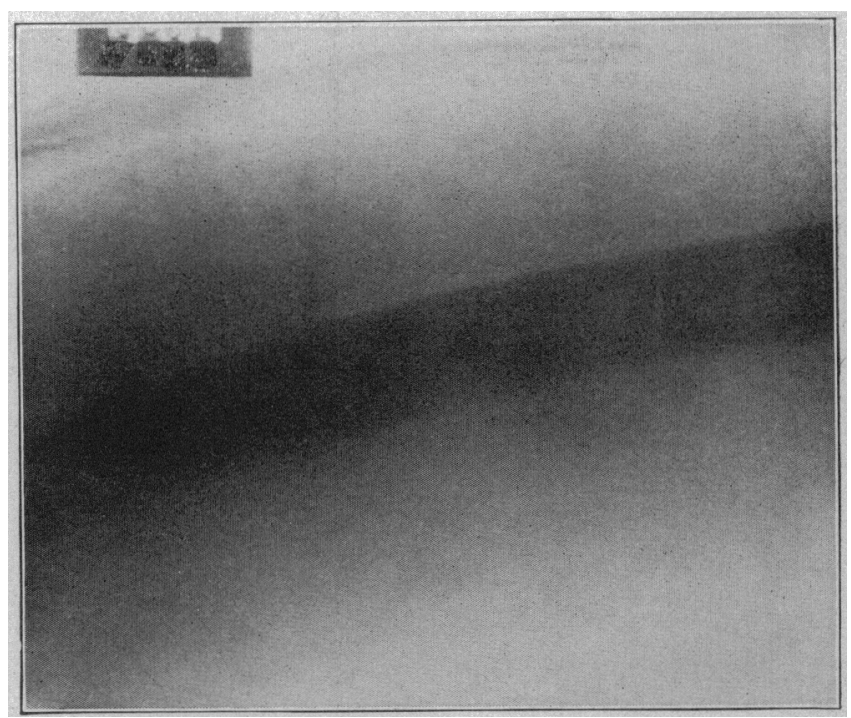

Fig. 10.-Reduction. by open method, of fracture shown in Figure 9 , showing perfict alignment. 
1. The open treatment of fractures insures practically anatomic reduction.

2. We lave overestimster the danger of making a compound out of a simple fracture.

3. The lane plate is the simplest and most efficient fixation device yet designed.

4. It insures immediate immobilization, which in turn means rapid repair and reduction of pain to a minimum.

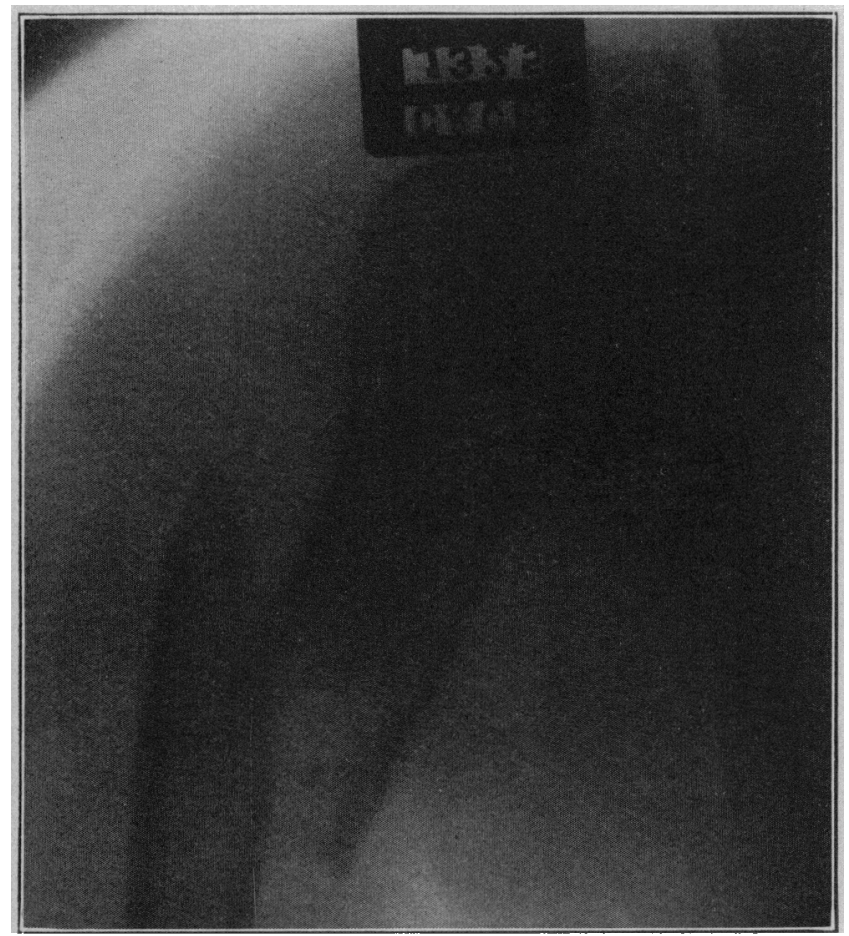

Fig. 11.-Comminuted fracture of left humerus with marked displacement and hematoma in axilla and on chest (Case 5 ).

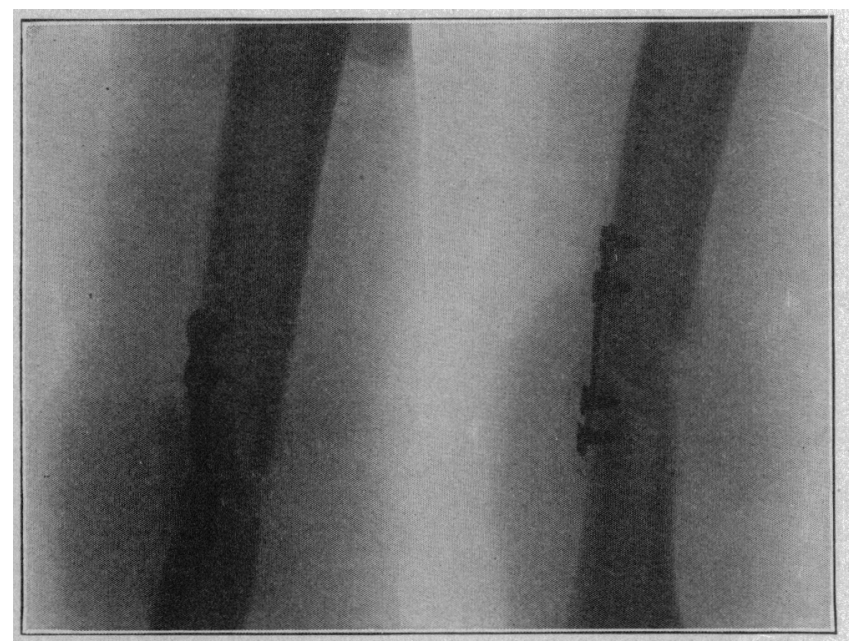

Fig. 13.-Compound, comminuted fracture of the left humerus with crushing of the soft parts. causied by being run over by a loaded wagon l'ase 6 ). Fragments of bone were removed and the fracture reduced and held in place by the bone plates. Tbe wound
healed without infection.

5. Its application is easier and requires less mutilation and smaller incision than the use of wire.

6. It is a great aid in the management of compound infected fractures.

¿. Direct mechanical fixation of fractures greatly simplifies after-treatment.
8. The $x$-ray has shaken our confidence in manuai reduction, and will force us to moro accurate methods.

In support of these conclusions [ wisl $_{1}$ to report six cases in which operation was done this year:

CAsE 1.-Man, aged 34. Compound infoted fracture of left radius, with inward displacement of lower fragment and fracture of ulna without displacement (Figs. 1 and 2). Arm, forearm and hand were greatly swollen from infection of a lacerated wound over the seat of the fracture, which prevented

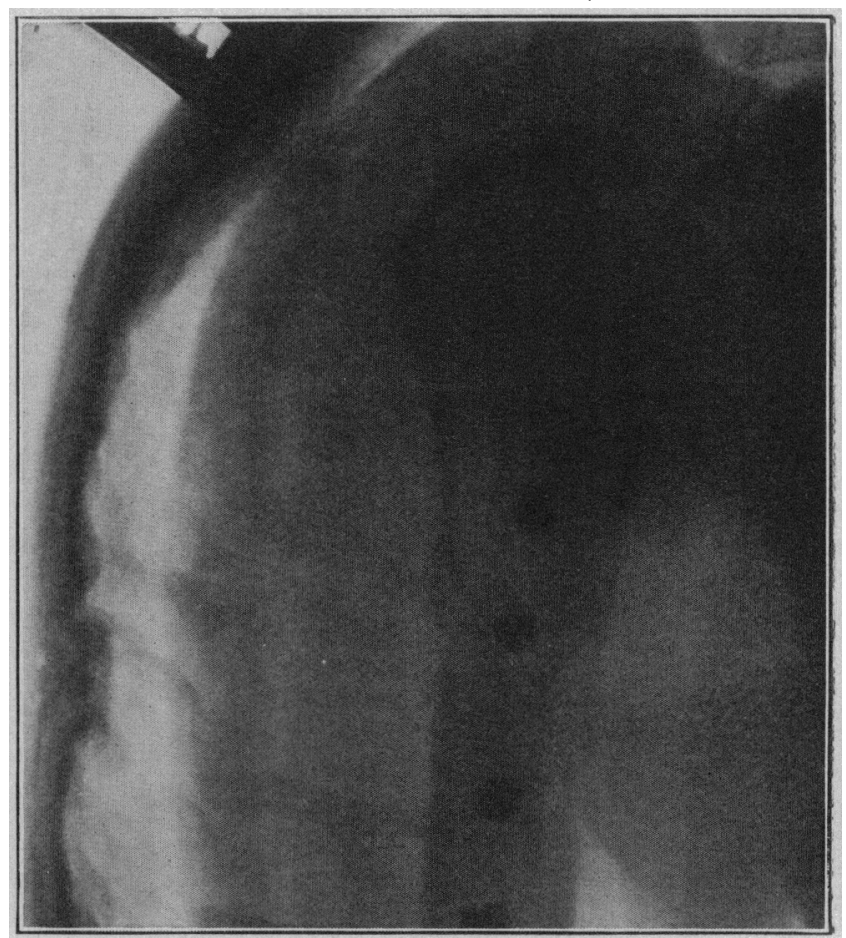

Fig. 12-Reduction, by open method, in case shown in Figure 11 some fragments of bone being removed, as shown in the radiograph.

any splinting. The limb was bound in pillows for ten days and the wound infection treated with moist antiseptic dressings. Three or four lays prior to operation a 10 per cent. balsam of Peru ointment was used. At time of operation the granulating wound was scrubbed with gatue and Harrington's solution until all gramulations were removed. The wound wi. closed entirely, except the space oceupied by a small cigarette drain, which was removed two days afterward. Union liy first intention was obtained. The result as to reduction is shrwn in the radiographs (Figs. 3 and 4 ).

Case 2.- Woman, aged 49. Fracture of left femur at middle of lower third, with tho usual backward displacement of upper end of lower fla; sat (Fig. 3). Reduction was attempted and thonght to be satisfactory. Radiograph proved this conclusion to be erroneous, or there was subsecuent dis. placement. Considerable difliculty was experienced at the operation to accomplish reduction. After application of plate convalescence was uneventful. The incision healed by first intention. The patient walked on the limb nine weeks after ope:ation, and measurement shows no shortening (Fig. 6).

CA: $: 3 .-$ Man, aged 44. Fracture of left humerus about five il: ohes above the olbow, involving the musculospiral groove Several attempts were made at reciuction, with and without anesthesia. Radiographs revealed marked forward displacement of the upper end of the lower fragment (Fig. 7 ). At operation the musculospiral nerve was fixed in the soft tissues by eatgut sutures. Convalescence was uneventful. Union of operation wound took place by first intention. Alionment in this case was not as good as it should have been, but was improved by splints and compresses (Fig. 8).

CASE 4.-Boy, aged 13. Fracture of upper third of left femur (Fig. 9). Three unsuccessful attempts were made at 
reduction. Reduction and alignment are shown by radiograph to be almost anatomic (Fig. 10), Convalescence was uneventful. Union occurred by first intention. There was no shortening.

CASE 5.-Man, aged 32. Comminuted fracture of left humerus, with marked displacement (Fig. 11). There was a large hematoma extending into the axilla and on the chest anteriorly and posteriorly. Operation was done nine days after the injury. I considered it safe to wait until the tissues had gained some resistance. Several fragments of bone were removed at the operation. Their absence is well shown in the radiograph (Fig. 12). Convalescence was uneventful, Union by first intention took place. The patient undressed and dressed himself without assistance thirty-two days after the operation.

CAsE 6.-Boy, aged 18. Compound comminuted fracture of the left humerus, caused by passage of two wheels of a loaded coal wagon $(7,450$ pounds) over the member. Operation was performed two days after the injury. The patient traveled 150 miles from an inaccessible part of the state. The comminuted fragments were removed. The extensor muscles of the arm were severed by the crushing force of the wheels. The musculospiral nerve was tucked into the lower segment of the triceps. There was no infection of wound, which healed kindly as soon as the devitalized soft parts separated. Alignment is well shown in the radiograph (Fig. 13). There was some paresis of the flexors and extensors of the forearm, but at the time of the last report (nine weeks after the injury) power was rapidly returning.

1723 Tremont Place.

\section{A METHOD OF TONSILLECTOMY BY MEANS OF A GUILLOTINE AND THE ALVEO- LAR EMINENCE OF THE MANDIBLE}

\section{GREENFIELD SLUDER, M.D.}

Clinical Professor for Diseases of the Nose and Throat, Medical Department of Washington University ST. LOUIS

I wish to describe a method of tonsillectomy which, so far as I can learn, has not heretofore been described or used. The essential and distinctive feature of this method is the fact that it moves the tonsil completely out of its normal bed in the forward and upward direction and then utilizes one of the anatomic markings of the lower jaw as a vantage-point in putting it through the aperture of the guillotine. This anatomic marking is the well-defined eminence just above the mylohyoid line, produced by the last-formed molar tooth in its socket (Fig. 1, a, Fig. 2, I, a, Fig. 2, II, a), which is rendered even more prominent in the mouth by the tissues of the gum. In childhood the posterior, unformed molar as it lies imbedded in the alveolus helps to make the eminence (Fig. 2, II, a). This marking has not been given a name in any of the treatises on anatomy. I have taken the liberty of naming it "the alveolar eminence of the mandible," in order to facilitate the description of this procedure.

The instrument used (Fig. 3, I and 3, II) is a modification of what I have nearly always heard called the "Mackenzie guillotine"; but it occasionally has been called the "English guillotine" to distinguish it from the "Mathieu" or "French guillotine." Sir Morell Mackenzie, ${ }^{1}$ however, relates that the instrument which nowadays bears his name is a modification of the one described by Dr. Physick ${ }^{2}$ of Philadelphia in 1827, the difference being that he (Mackenzie) made the handle

1. Mackenzie, Morell : Diseases of the Pharynx, Larynx and Trachea, New York, Wm. Wood \& Co., 1880.

2. Physick : Am. Jour. Med. Sc., i, 262, Quoted bs Mackenzit. reversible, so that it could be applied to either side of the shaft. In this way he facilitated its use by surgeons who used the one hand for removing both tonsils. He also narrates that Dr. W. B. Fahnestock ${ }^{3}$ of Lancaster, Pa., in 1832, first described the modification which consists of a circular aperture and a transfixing needle, with a ring. knife to cut on the pull (the

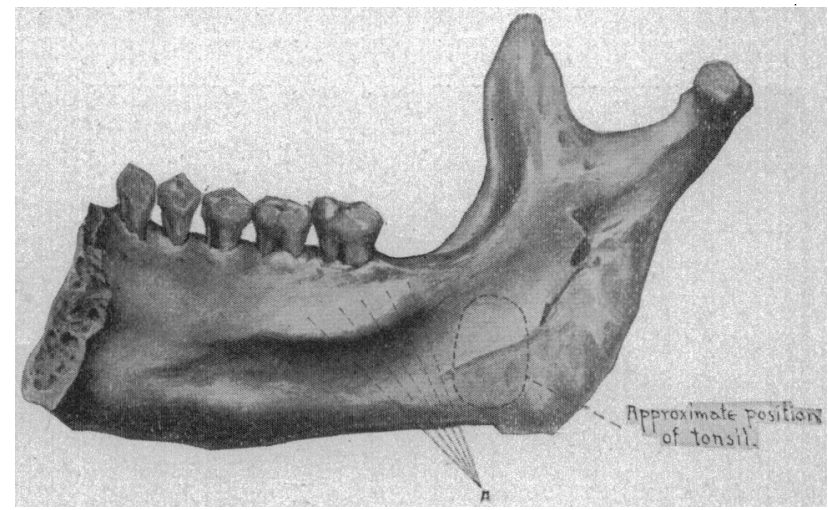

Fig. 1.-Inner surface of the right half of the mandible, showing the alveolar eminence, $A$, and its relation to the usual position of the tonsil.

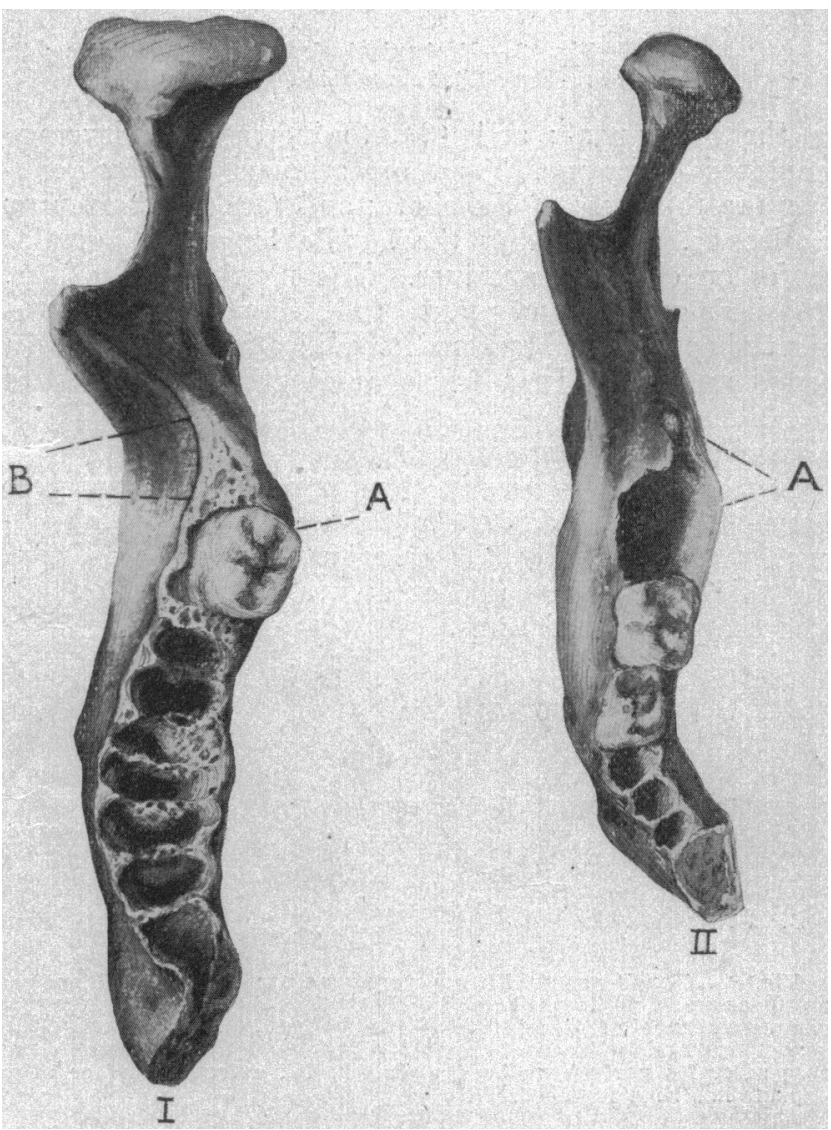

F:g. 2.-I. Right half of a mature mandtble seen from above, showing alveolar eminence, $A$, with fully cut third molar and buccinator ridge $B$. II. Right half of young mandivle seen trom above, showing uncut third molar and the part it takes in the formation of the alveolar eminence $A$.

"French guillotine") and that Guersant" in 1864 changed the shape to an ellipse and at the suggestion of Velpeau added the elevating prongs. He furthermore states that the guillotine idea was first published

3. Fahnestock, W. B.: Am. Jour. Med. Sc., xi, 248. Quoted by Mackenzle.

4. Guersant: Hypertrophle des amygdales, Paris, 1864. Quoted by Mackenzie. 